\title{
Efeito do Teor de Carbono do Metal de Base e da Alma do Eletrodo Revestido Sobre a Porosidade em Soldas Molhadas
}

\author{
(The Effect of Base Metal and Core Rod Carbon Content on Underwater Wet Welds Porosity)
}

\begin{abstract}
Luciano G. D. Andrade , Weslley C. Dias ${ }^{1}$, Leandro F. Ribeiro', Alexandre Q. Bracarense', Ezequiel C. P. Pessoa ${ }^{2}$, Stephen Liu ${ }^{3}$ ${ }^{1}$ Universidade Federal de Minas Gerais, Departamento de Engenharia Mecânica/Laboratório de Robótica, Soldagem e Simulação, BeloHorizonte,Minas Gerais, Brasil,lgandrade@yahoo.com.br,weslleycds@yahoo.com.br, leandrofr86@gmail.com, bracarense@ ufmg.br

${ }^{2}$ Instituto Federal de Educação, Ciência e Tecnologia de Minas Gerais, Campus Congonhas, Congonhas, Minas Gerais, Brasil, ecpp76@gmail.com

${ }^{3}$ Colorado School of Mines, Center for Welding, Joining and Coatings Research, Golden, Colorado, Estados Unidos, sliu@mines.edu
\end{abstract}

\section{Resumo}

Porosidade é um defeito comum em soldagem subaquática molhada. Vários estudos têm sido realizados com o objetivo de avaliar os mecanismos que controlam sua formação e assim encontrar soluções para minimizá-la ou eliminá-la. Este trabalho tem como objetivo avaliar o efeito da variação dos teores de carbono do metal de base e da alma do eletrodo sobre a porosidade do metal de solda. Dois diferentes metais de base, com variações apenas no teor de carbono (C2 - 0,1\% e C7 - 0,7\%), foram utilizados para deposição das soldas feitas à 50 metros de profundidade, utilizando eletrodos comerciais E6013 com diferentes teores de carbono na alma (E2 0,002\% e E6 -0,6\%), em polaridade direta (DCEN). O método macrográfico de análise de imagens foi utilizado para a quantificação da porosidade. Utilizando os metais de base C2 e C7, observou-se que a porosidade aumentou significativamente com o aumento do teor de carbono da alma do eletrodo. Em contrapartida, observou-se uma redução da porosidade com o aumento do teor de carbono do metal de base utilizando-se os eletrodos E2 e E6.

Palavras-chave: Soldagem Subaquática Molhada; Porosidade; Concentração de Carbono no Metal de Base e Alma do Eletrodo.

\begin{abstract}
Porosity is a very common defect observed in underwater wet welding. Several researches have been developed to understand its formation mechanisms in order to mitigate the problem. The main objective of this project is to study the effect of base metal and core rod carbon content at weld metal porosity. Bead-on-plate were made on two different base metal carbon content (C2 - 0.1 wt. pct. and C7 - 0.7 wt. pct.) at 50 meters water depth, using commercial E6013 electrodes covered with varnish. Electrodes with different carbon content in core rod were used (E2 - 0.002 wt. pct. and E6 - 0.6 wt. pct.) in polarity negative (DCEN). Macrographic method (image analysis) was used to porosity quantification. Using the basic metals $C 2$ and $C 7$, it was observed that the porosity increased significantly with increasing core rod carbon content. In contrast, there was a reduction in porosity with increasing the base metal carbon content, using the electrodes E2 and E6.
\end{abstract}

Key-words: Underwater Wet Welding; Porosity; Base Metal and Core Rod Carbon Content.

\section{Introdução}

O estudo da porosidade em soldagem subaquática molhada tem sido o tema de vários trabalhos $[1,2]$ de pesquisa na área nos últimos anos uma vez que a porosidade é um problema muito comum. Este trabalho pretende trazer contribuições para as pesquisas nessa área, através de uma investigação sobre alguns fatores que podem influenciar a porosidade neste tipo de solda.

(Recebido em 30/03/2010; Texto final em 21/06/2010).

Artigo originalmente publicado no CONSOLDA 2009,

Piracicaba, SP, Outubro de 2009.
A porosidade é, provavelmente, um dos principais defeitos em soldagem subaquática molhada, juntamente com a perda de elementos de liga e inclusões não-metálicas, que provoca redução dos limites de escoamento e de ruptura, da ductilidade e da tenacidade da junta soldada. $\mathrm{O}$ aumento da profundidade ou pressão hidrostática de soldagem aumenta a porosidade do metal de solda a níveis que podem ser inaceitáveis para certas aplicações [4 - 6].

Pessoa [2] relatou que a porosidade, além de variar com a profundidade, como pode ser observado na Figura 1, depende também do tipo de revestimento do eletrodo. Neste estudo [2], o eletrodo rutílico produziu soldas com menor porosidade que o eletrodo básico. Adicionalmente, e conforme já relatado em estudos anteriores [6], a porosidade foi consideravelmente maior na polaridade direta (DCEN). 


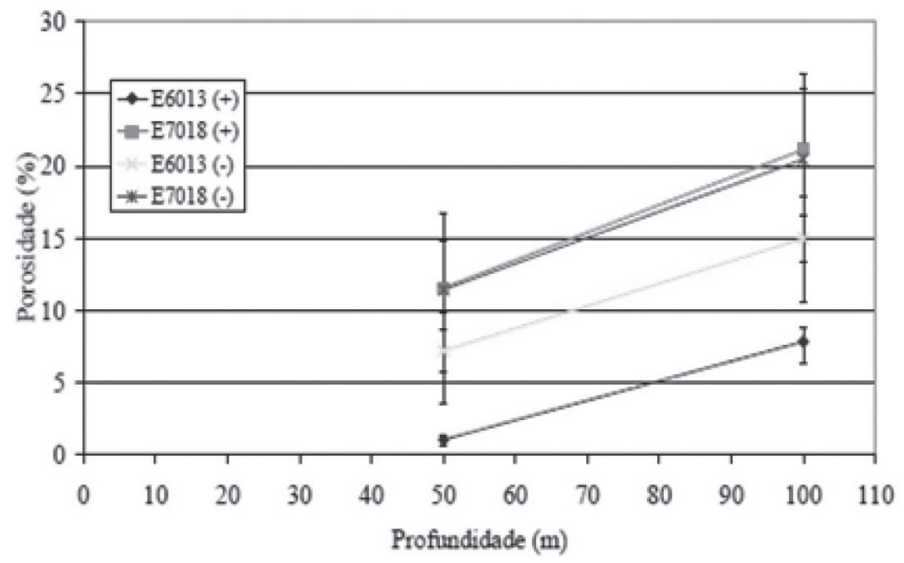

Figura 1. Variação da porosidade em função da profundidade, polaridade e tipo de eletrodo [2].

Nesse trabalho [2] estudou-se a variação da composição química e da porosidade ao longo do cordão de soldas subaquáticas molhadas. Foram depositados cordões sobre chapa com os eletrodos E6013 e E7018, na polaridade direta (DCEN) e inversa (DCEP), nas profundidades de 50 e $100 \mathrm{~m}$. Observouse que o teor de carbono no metal de solda aumentou enquanto a porosidade reduziu do início para o fim do cordão de solda, com exceção do eletrodo E6013 em DCEN a 50 m e do eletrodo E7018 em DCEN a 100m. Esse comportamento inverso entre a porosidade e o teor de carbono foi relacionado á redução do número de curtos circuitos e conseqüente diminuição na formação de $\mathrm{CO}$ na gota metálica durante a transferência ao longo da deposição. Transferência do tipo curto circuito implica em maior tempo de exposição da gota metálica a atmosfera do arco elétrico e, conseqüentemente, maior queima de carbono e geração de CO. Isso explicou o aumento do teor de carbono no metal de solda no final do cordão, exatamente onde se detectou menor porosidade e menor ocorrência de curtos circuitos. No gráfico da Figura 2 pode ser observada a variação da porosidade ao longo do cordão em deposições sobre chapa. Esta mesma tendência foi detectada em soldas depositadas em chanfro, como pode ser observado nas radiografias das Figuras 3 e 4 .

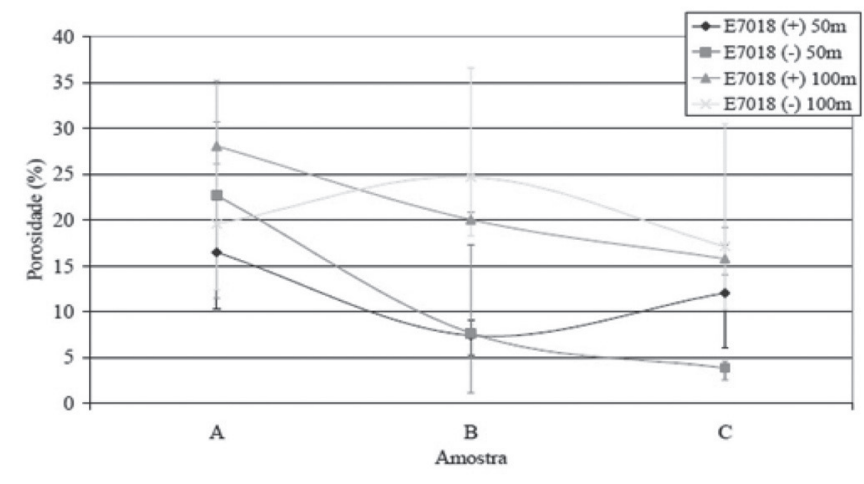

Figura 2. Variação da porosidade ao longo do cordão para o eletrodo E7018, nas polaridades DCEN e DCEP, às pressões de 50 e $100 \mathrm{~m}$ [2].

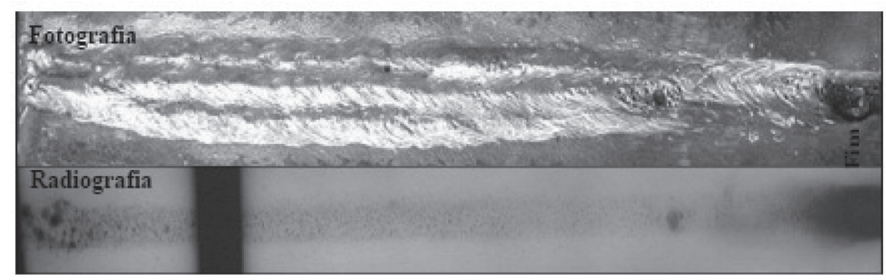

Figura 3. Radiografia de solda feita a 50 metros em aço A-36 com o Eletrodo E6013 [3].

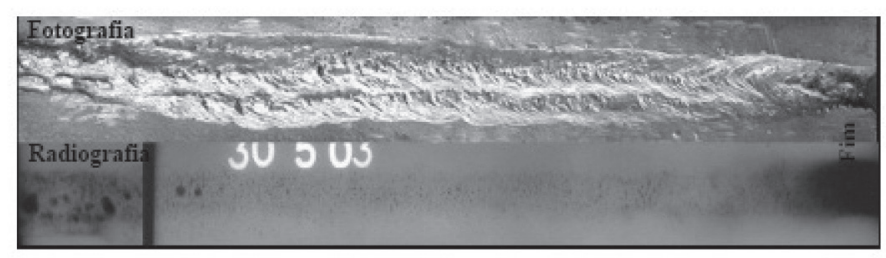

Figura 4. Radiografia de solda feita a 100 metros em aço A-36 com o Eletrodo E6013 [3].

O resultado da porosidade final no metal de solda depende basicamente de fatores como: transferência de gases para a poça de fusão, geração de gases por reações químicas na poça de fusão e quantidade de gases que escapam da poça de fusão que está ligada a variações na taxa de resfriamento do metal de solda e de propriedades da escória.

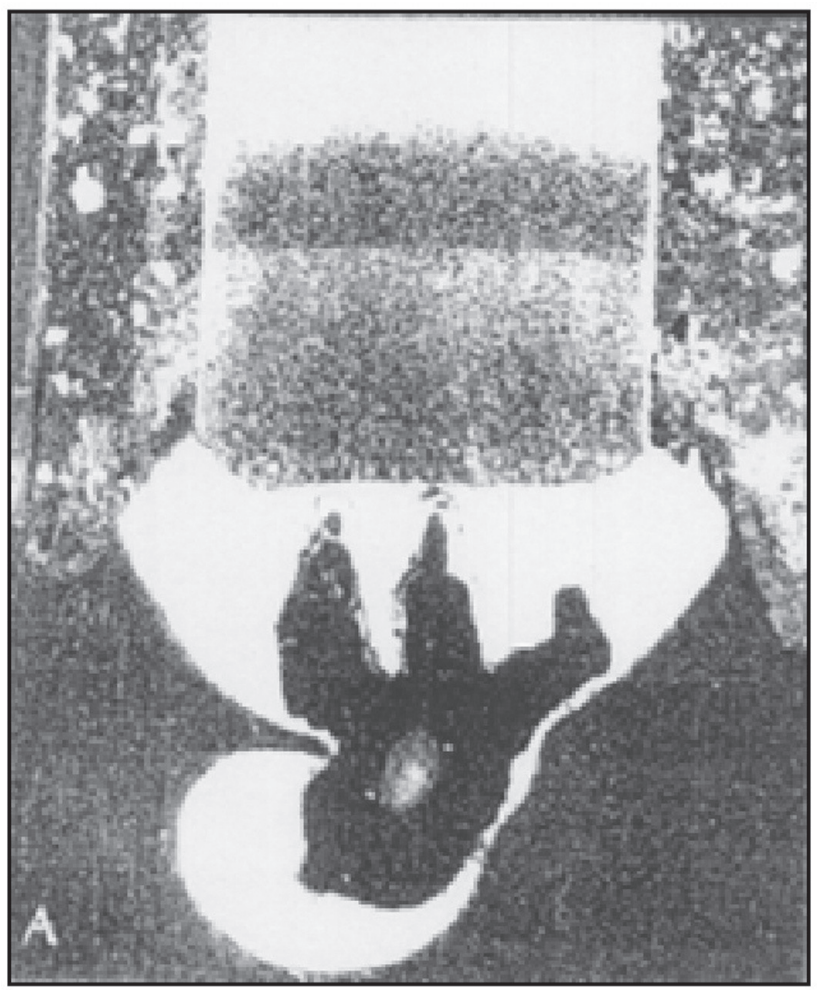

Figura 5. Bolha de gás formada no interior da gota metálica [11].

Semelhantemente ao que ocorre em fundição, a formação dos poros é controlada pela solubilidade de vários gases (principalmente o hidrogênio e o oxigênio) na poça de fusão e 
no metal fundido [7-8]. Com o resfriamento, a solubilidade dos gases no metal líquido é reduzida, formando assim bolhas de gases. O resfriamento e a solidificação em soldagem subaquática são rápidos o suficiente para impedir que as bolhas escapem do metal de solda pela ação da força de empuxo. Desta forma, estas bolhas ficam retidas no metal solidificado formando os poros [9]. Para exemplificar, a solubilidade do hidrogênio no ferro líquido é de 23,6 ml/100 g, e no ferro no estado sólido, a temperaturas inferiores a $500^{\circ} \mathrm{C}$, esta solubilidade cai para $1,0 \mathrm{ml} / 100 \mathrm{~g}$ [10].

Brandi et al [11], soldando ao ar, observou a ocorrência de porosidade na gota metálica, mostrado nas Figuras 5 e 6, que quando incorporada na poça de fusão poderia contribuir na porosidade final do metal de solda solidificado.

Perez [1] propôs que a maior parte dos gases responsáveis pela formação dos poros em soldagem molhada são formados na gota de metal líquida na ponta do eletrodo revestido durante o processo de transferência metálica, como reportado por Brandi et al [11]. Perez [1] mostrou que, para teores de carbono da alma de $0,05 \%$, a oxidação de somente $20 \%$ do carbono contido nas gotas de 0,5 a 5,0 $\mathrm{mm}$ de diâmetro é suficiente para produzir bolhas de gás de $\mathrm{CO}$ com um volume duas vezes maior que o volume das gotas, Figura 7.

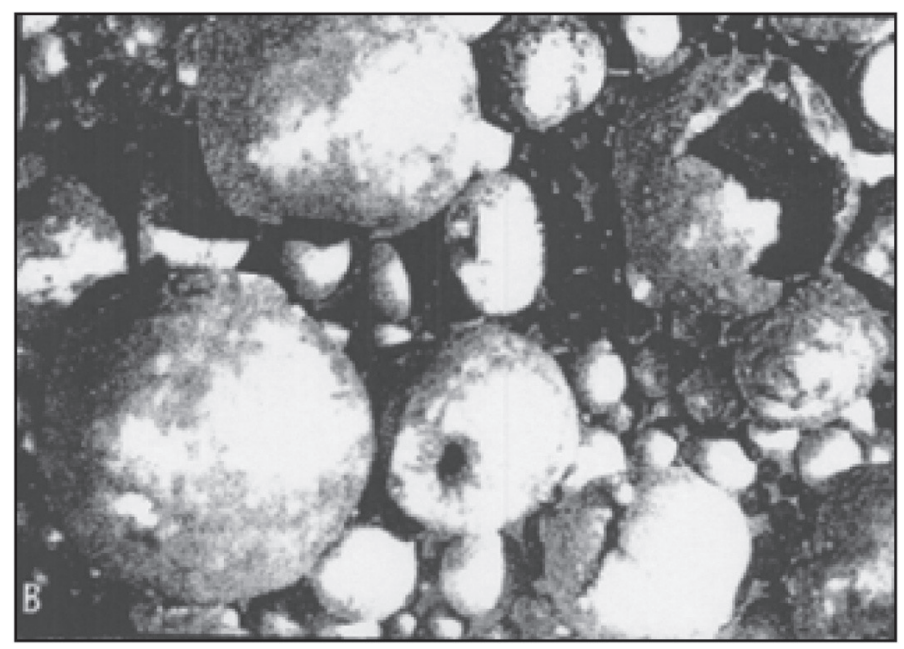

Figura 6. Gotas metálicas coletadas após a remoção da escória [11].

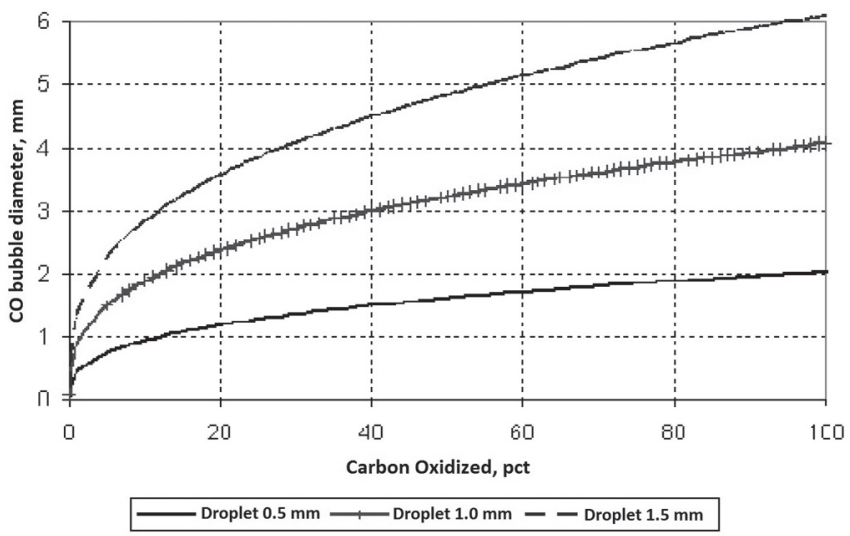

Figura 7. Relação entre carbono oxidade e Bolhas de CO produzidas dentro das gotas de metal de aço com teor de carbono de $0,05 \%$ [1].
Nas gotas, gases, principalmente monóxido de carbono, resultante da reação do carbono com oxigênio, são absorvidos e transferidos para a poça de fusão. Conforme o metal líquido se resfria e se solidifica, estes gases são aprisionados no metal de solda, formando poros. Baseado no que ocorre em fundição [12], Pessoa [2] relatou que em soldagem subaquática molhada a formação de $\mathrm{CO}$ é mais influente na nucleação do poro, enquanto a difusão de hidrogênio é mais efetiva em promover o crescimento do poro. Assim, os gases transportados para a poça de fusão dentro das gotas metálicas podem ter uma contribuição muito importante para a porosidade final do metal de solda. O modelo que descreve a formação do poro nas gotas de metal, proposto por Pessoa [2], é ilustrado na Figura 8.

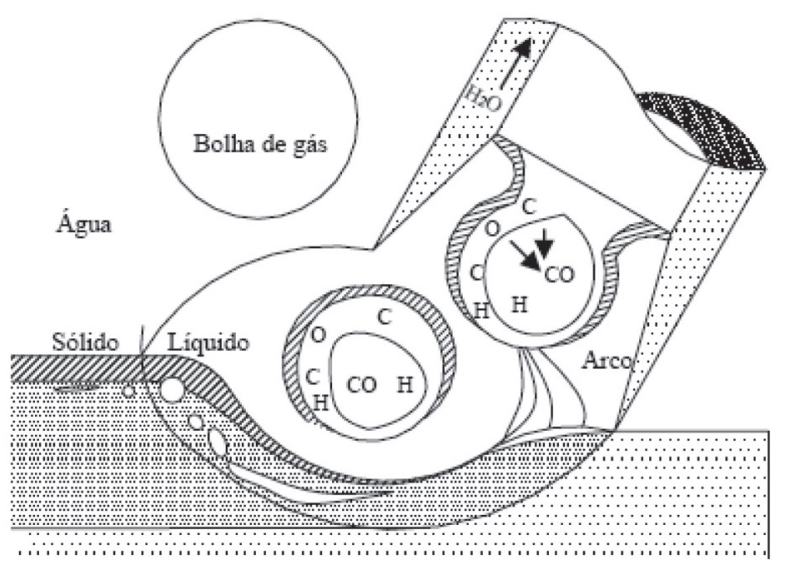

Figura 8. Formação de bolhas de gás no interior da gota metálica [2].

Diversos pesquisadores [5, 6, 14 e 22] investigaram a composição química dos gases contidos dentro dos poros, mostrados na Tabela 1. Estes resultados contraditórios, especialmente em relação aos teores de $\mathrm{CO}$ e $\mathrm{H} 2$, indicam que a real contribuição da molécula de $\mathrm{CO}$ na formação de poros em soldagem subaquática molhada não é ainda bem estabelecida.

Tabela 1. Composição química dos poros de soldas molhadas.

\begin{tabular}{|c|c|c|c|c|}
\hline $\begin{array}{c}\text { (Composição química } \\
\text { do gás vol.pct) }\end{array}$ & $\mathrm{H}_{2}$ & $\mathrm{CO}$ & $\mathrm{CO}_{2}$ & Outros \\
\hline Suga \& Hasui & 96 & 0.4 & 0.06 & -- \\
\hline Silva & $62-82$ & $11-24$ & $4-6$ & -- \\
\hline Gooch & 45 & 8 & 4 & 4 \\
\hline Liu \& Olson & $20-30$ & $70-80$ & -- & -- \\
\hline
\end{tabular}

Neste trabalho, pretende-se verificar a influência do teor de carbono da alma do eletrodo e do metal base na porosidade do metal de solda. Sabe-se que o carbono na alma do eletrodo contribui para a formação das bolhas no interior da gota, na ponta do eletrodo durante a sua transferência para a poça de fusão [1]. Acredita-se que o carbono no metal base contribui para a formação dos poros na poça de fusão que, juntamente com os gases formados no interior das gotas, resultarão na porosidade final do metal de solda [2]. 


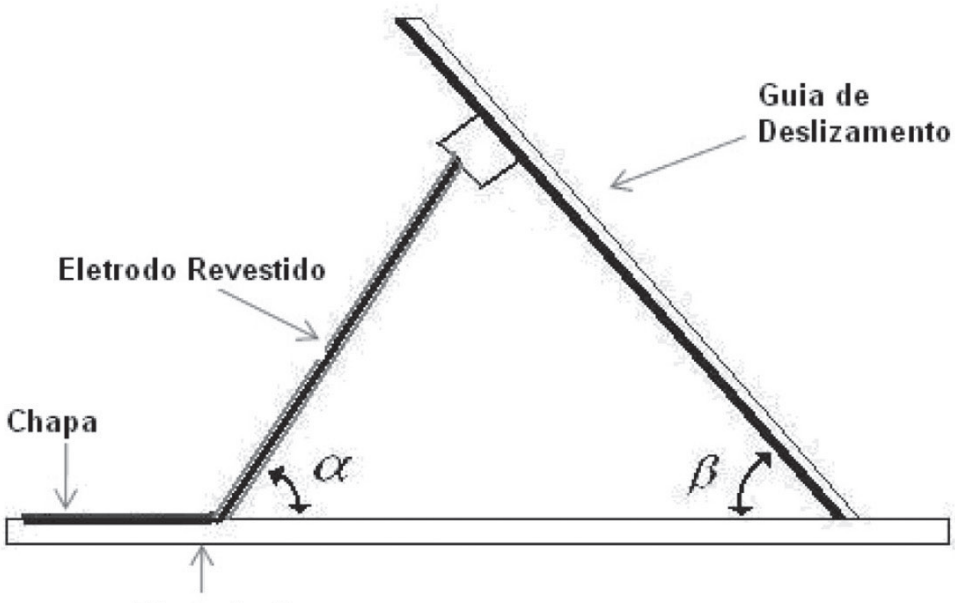

Plano de Base

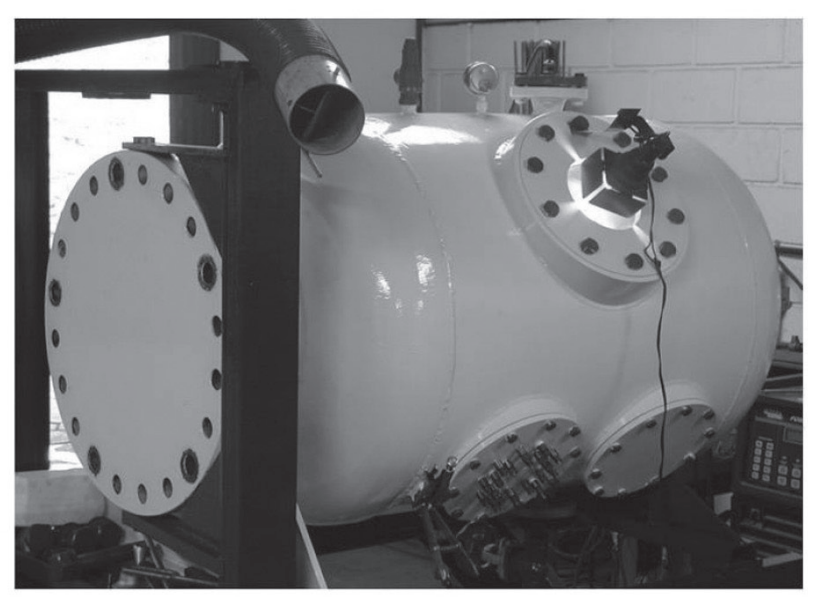

b)

Figura 9: a) Esquema do sistema de soldagem por gravidade e b) Tanque hiperbárico para soldagem subaquática.

\section{Materiais e Métodos}

As soldas foram realizadas utilizando um sistema de soldagem por gravidade dentro de um tanque hiperbárico capaz de simular profundidades equivalentes de até 200 metros. Um esquema representativo do sistema de soldagem por gravidade e o tanque hiperbárico estão mostrados na Figura 9.

Eletrodos rutílicos E6013 de 4,0 mm de diâmetro da alma e comprimento de $350 \mathrm{~mm}$ foram utilizados. Para a fabricação dos eletrodos, dois tipos diferentes de arames para a alma foram utilizados. O primeiro com a composição química contendo baixíssimo teor de carbono, 0,002\%, e carbono equivalente $(\mathrm{CE})$, calculado pela Equação 1, de aproximadamente $0,01 \%$, identificado como E2. O segundo, identificado como E6, contém aproximadamente $0,62 \%$ de carbono e de carbono equivalente, resultante do processo de cementação realizado nos arames do tipo E2. Dessa maneira, a principal diferença entre os dois eletrodos utilizados está no teor de carbono da alma. A composição química das almas dos eletrodos está mostrada na Tabela 2.

$C_{e q}=\% C+\frac{\% M n}{6}+\frac{\% C r+\% M o+\% V}{5}+\frac{\% N+\% C u}{15}$

Tabela 2. Composição química da alma dos eletrodos utilizados

\begin{tabular}{|c|c|c|c|c|c|}
\hline Eletrodo & $\mathrm{CE}$ & $\mathrm{C}$ & $\mathrm{Mn}$ & $\mathrm{Si}$ & $\mathrm{Cr}$ \\
\hline \multirow{3}{*}{ E2 } & \multirow{3}{*}{0.01} & 0.002 & 0.05 & $\begin{array}{c}\text { Não } \\
\text { detectado }\end{array}$ & 0.018 \\
\hline & & Mo & $\mathrm{Cu}$ & $\mathrm{V}$ & $\mathrm{Ni}$ \\
\hline & & 0.001 & 0.01 & $\begin{array}{c}\text { Não } \\
\text { detectado }\end{array}$ & $\begin{array}{c}\text { Não } \\
\text { detectado }\end{array}$ \\
\hline Eletrodo & $\mathrm{CE}$ & $\mathrm{C}$ & $\mathrm{Mn}$ & $\mathrm{Si}$ & $\mathrm{Cr}$ \\
\hline \multirow{3}{*}{ E6 } & \multirow{3}{*}{0.62} & 0.62 & 0.05 & 0.04 & 0.02 \\
\hline & & Mo & $\mathrm{Cu}$ & $\mathrm{V}$ & $\mathrm{Ni}$ \\
\hline & & 0.001 & 0.001 & 0.004 & 0.01 \\
\hline
\end{tabular}

Para depósito dos cordões de solda, chapas de aço com dimensões de 4,765 x 150 × $250 \mathrm{~mm}$ com diferentes teores de carbono foram utilizadas. Chapas de aço AISI 1010 com 0,10\% de carbono e CE de 0,24\%, foram identificadas como C2. Chapas do mesmo material cementadas para terem um teor aproximado de $0,66 \%$ de carbono e CE de $0,70 \%$ foram identificadas como C7. A Tabela 3 mostra a composição química dos metais de base utilizados.

Tabela 3. Composição química dos metais de base utilizados

\begin{tabular}{c|c|c|c|c|c}
\hline \multirow{2}{*}{ Base Metal } & \multicolumn{2}{c}{ EC } & \multicolumn{2}{c}{$\mathrm{C}$} & \multicolumn{2}{c}{$\mathrm{Mn}$} & \multicolumn{2}{c}{$\mathrm{Si}$} & $\mathrm{Cr}$ \\
\hline \multirow{2}{*}{$\mathrm{C} 2$} & \multirow{3}{*}{0.24} & 0.11 & 0.77 & 0.06 & 0.01 \\
\cline { 3 - 6 } & & $\mathrm{Mo}$ & $\mathrm{V}$ & $\mathrm{Cu}$ & $\mathrm{Ni}$ \\
\cline { 3 - 6 } & & 0.01 & 0.004 & 0.01 & $<0.011$ \\
\hline \multirow{2}{*}{ Base Metal } & $\mathrm{EC}$ & $\mathrm{C}$ & $\mathrm{Mn}$ & $\mathrm{Si}$ & $\mathrm{Cr}$ \\
\hline \multirow{2}{*}{$\mathrm{C} 7$} & & 0.66 & 0.72 & 0.06 & 0.01 \\
\cline { 3 - 6 } & \multirow{2}{*}{0.70} & $\mathrm{Mo}$ & $\mathrm{V}$ & $\mathrm{Cu}$ & $\mathrm{Ni}$ \\
\cline { 3 - 6 } & & $<0.005$ & 0.004 & 0.03 & $<0.011$ \\
\hline
\end{tabular}

Testes preliminares foram realizados para se definir a melhor corrente de soldagem mantendo-se os ângulos do dispositivo de soldagem constantes em $\alpha=60^{\circ}$ e $\beta=80^{\circ}$. Os parâmetros foram escolhidos baseando-se na aparência superficial dos cordões. As correntes testadas foram de 160, $170,190,210$ e 230 ampères, e a que resultou em um cordão de solda com a melhor aparência superficial foi o feito com a corrente de 210 ampères. A Tabela 4 mostra os parâmetros de soldagem aplicados na fonte de corrente constante. Todos os testes foram realizados a uma profundidade equivalente de 50 metros, utilizando polaridade direta (DCEN). 
Tabela 4. Parâmetros de soldagem utilizados para os testes

\begin{tabular}{c|c|c|c}
\hline Profundidade $(\mathrm{m})$ & Ângulo $\alpha$ & Ângulo $\beta$ & Corrente (A) \\
\hline 50 & 60 & 80 & 210 \\
\hline
\end{tabular}

Três deposições sobre chapa foram feitos para cada combinação eletrodo/metal de base (E2-C2 E2-C7 E6-C2 E6C7) totalizando 12 cordões de solda. Cada cordão de solda foi transversalmente seccionado em três pontos diferentes ao longo do comprimento para análise macrográfica de morfologia e de porosidade do cordão. As amostras foram metalograficamente preparadas, devidamente lixadas, polidas e atacadas com solução Nital 2\% para a medição da área dos poros contidos em cada seção, da área do cordão de solda e das suas dimensões, tais como reforço, largura e penetração. A porosidade é dada pela relação entre a área de poros e a área total do cordão. Tal medição foi feita através do software Quantikov [12]. A partir das medições de porosidade, calculou-se o valor médio e o desvio padrão para cada grupo de amostras.

Os sinais de corrente e tensão de soldagem foram captados por uma placa de aquisição de dados e a freqüência utilizada foi de $1 \mathrm{KHz}$. Os valores médios de tensão, corrente de soldagem e número de curtos-circuitos foram calculados. Considerou-se como curto-circuito cada momento em que a tensão de soldagem for inferior a $5 \mathrm{~V}$, sendo que o número de curtos-circuitos é dado pela quantidade de vezes que isso acontece dentro do intervalo que abrange o décimo e o décimo quinto segundo de cada cordão de solda.

\section{Resultados e Discussão}

A Figura 10 mostra as soldas produzidas e a Figura 11 mostra as macrografias representativas para cada combinação eletrodo/metal de base testado.

Os cordões de solda feitos usando os mesmos eletrodos e mesmo metal de base apresentaram uma aparência superficial semelhante. Em relação à morfologia do cordão de solda, o reforço e a penetração diminuíram para os eletrodos com maiores teores de carbono na alma. As irregularidades superficiais aumentaram quando se utilizou eletrodos com maiores teores de carbono, e diminuíram quando se utilizou o metal de base com maior teor de carbono.

A Figura 12 mostra os resultados de porosidade no metal de solda para cada combinação eletrodo/metal de base. Como pode ser observado, a porosidade aumentou significativamente quando o eletrodo com maior teor de carbono (E6) foi usado. Estas observações indicam que o maior teor de carbono na alma do eletrodo foi efetivo no mecanismo de formação de bolha de $\mathrm{CO}$ dentro da gota líquida. Posteriormente, as bolhas foram transferidas para a poça de fusão resultando em maior formação de poros após a solidificação do metal, considerando-se que a quantidade de gases que escaparam foi constante para todos os eletrodos testados.

A Figura 13 mostra a tensão de soldagem e o número de curtos-ciruitos (NCC). O metal de base e eletrodo de alma com maior teor de carbono apresentaram menores valores de tensão e maior número de curtos-circuitos durante a soldagem. Menor tensão de soldagem e maior número de curtos-circuitos implicam em maior tempo para as reações de oxidação que ocorrem na gota metálica líquida. Maior número de curtos-circuitos também implica em menor proteção da gota. Durante cada curto-circuito, a proteção gasosa da gota é interrompida, pois neste momento o arco é interrompido. Assim, um maior número de curtoscircuitos é uma melhor condição para a reação de $\mathrm{CO}$ ocorrer e, consequentemente, maior quantidade de gás ser transferida pela gota para a poça de fusão.
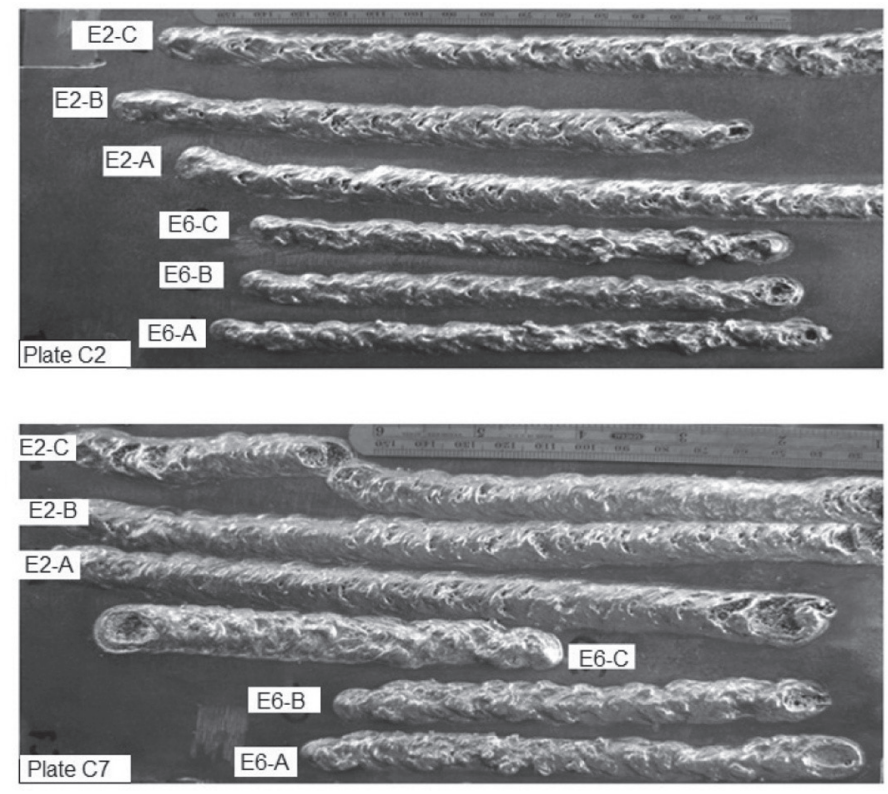

Figura 10: Cordões de solda realizados.

A Figura 12 também mostra que a porosidade diminuiu quando o metal de base com o maior teor de carbono (C7) foi utilizado. Estes resultados podem ser explicados juntamente com os resultados das medições da morfologia do cordão de solda mostrados na Figura 14. Como pode ser observado, a penetração e o reforço do cordão de solda aumentaram quando o metal de base com menor teor de carbono (C2) foi utilizado. A maior penetração do cordão de solda, até mesmo para o aço (C2), pode disponibilizar mais carbono do metal de base para reação com o oxigênio na poça de fusão líquida. Desta maneira, mais gases são gerados e o caminho para que os mesmos atinjam a superfície do cordão torna-se mais longo, diminuindo a possibilidade de os mesmos escaparem do metal líquido e aumentando a porosidade.

Modificações na morfologia do cordão de solda, juntamente com variações no teor de carbono do metal de base podem estar relacionada com a direção de fluxo de metal líquido na poça de fusão. Elementos ativos de superfície, como o oxigênio, tendem a segregar na superfície da poça de fusão líquida. Um gradiente de tensão superficial também será estabelecido promovendo o fluxo radialmente para fora. A consequiência deste fenômeno, Convecção de Marangoni, é a redução na penetração da solda [13]. Como o carbono reage com o oxigênio em altas temperaturas na poça de fusão, a reação carbono-oxigênio irá também diminuir a quantidade de oxigênio disponível no metal líquido e, por conseguinte, pode reduzir a penetração. Desta forma, o carbono pode ser considerado como um elemento 

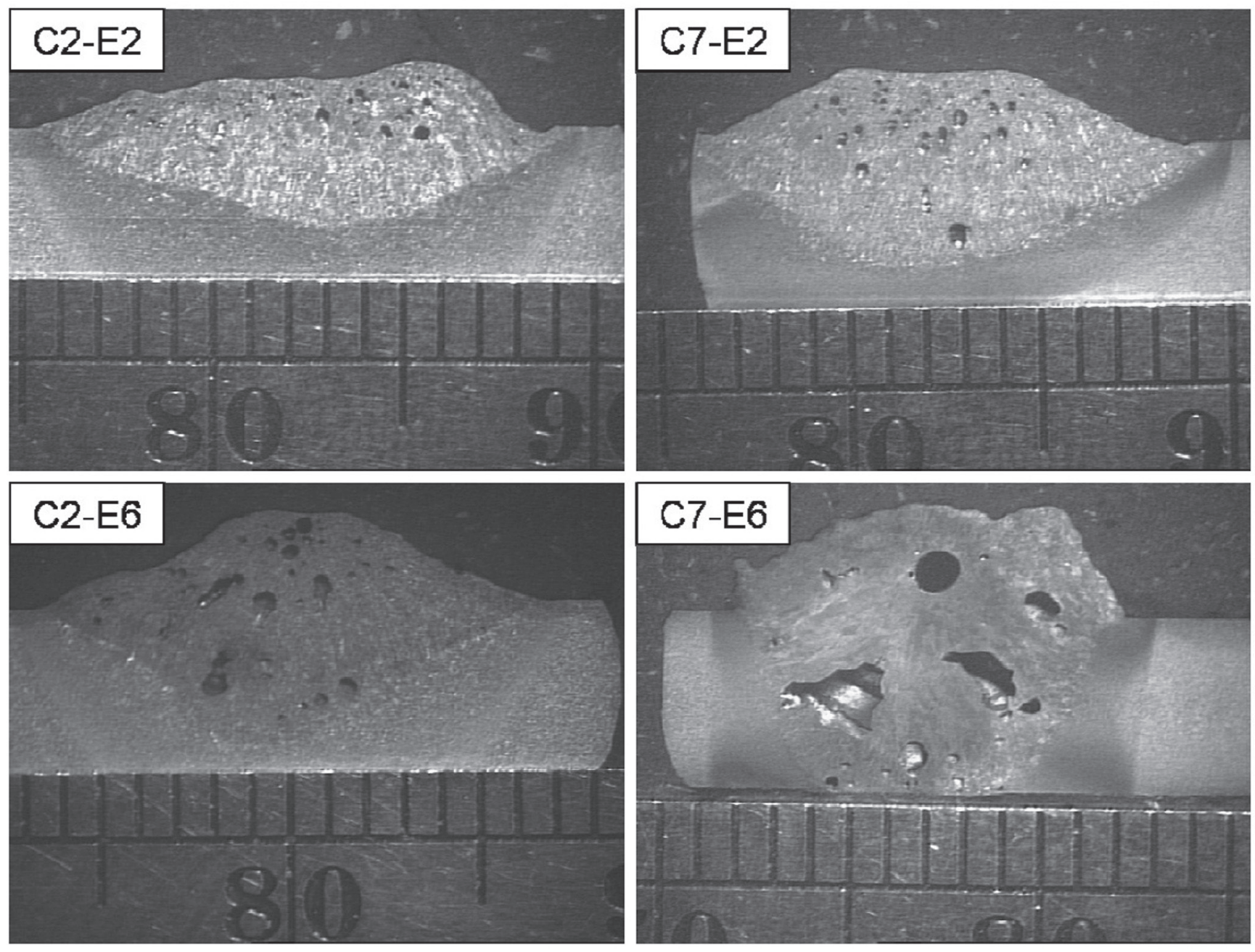

Figura 11: Macrografias dos cordões de solda.

reativo na convecção na poça de fusão líquida. Vários autores têm reportado a convecção na poça de fusão e o seu efeito na morfologia do cordão de solda [14 - 21].

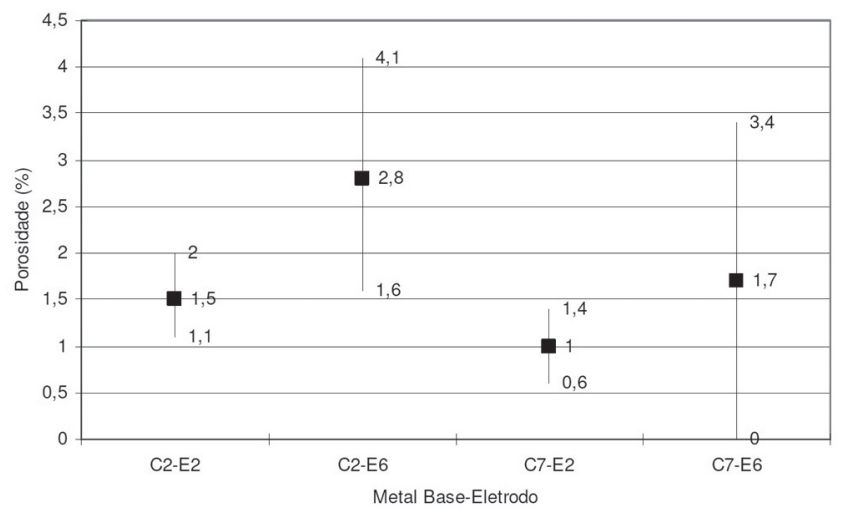

Figura 12: Porosidade do Metal de Solda

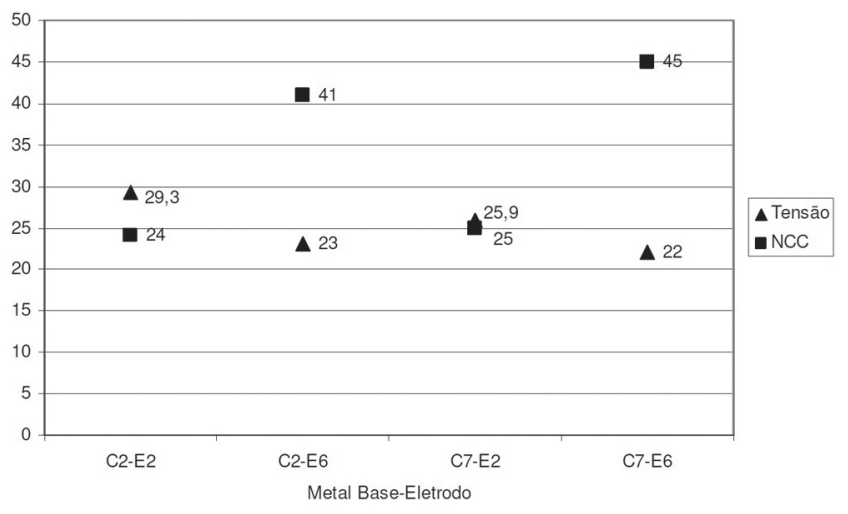

Figura 13: Tensão média de soldagem e número de curtoscircuitos (NCC) entre o décimo e o décimo quinto segundo de soldagem.

Com o objetivo de melhor caracterizar os efeitos do teor de carbono na alma do eletrodo e metal de base sobre a porosidade do metal de solda, alguns parâmetros relacionados à morfologia dos poros e sua distribuição foram analisados. A Figura 15 
mostra o efeito do teor de carbono no diâmetro do poro. O diâmetro médio dos poros aumentou com o aumento do teor de carbono na alma do eletrodo. Conforme o teor de carbono aumenta, a quantidade de $\mathrm{CO}$ aumenta, formando mais poros; com crescimento, os poros podem crescer e exibir maiores diâmetros. Com relação ao metal de base, nenhuma tendência no diâmetro dos poros com o teor de carbono foi observada.
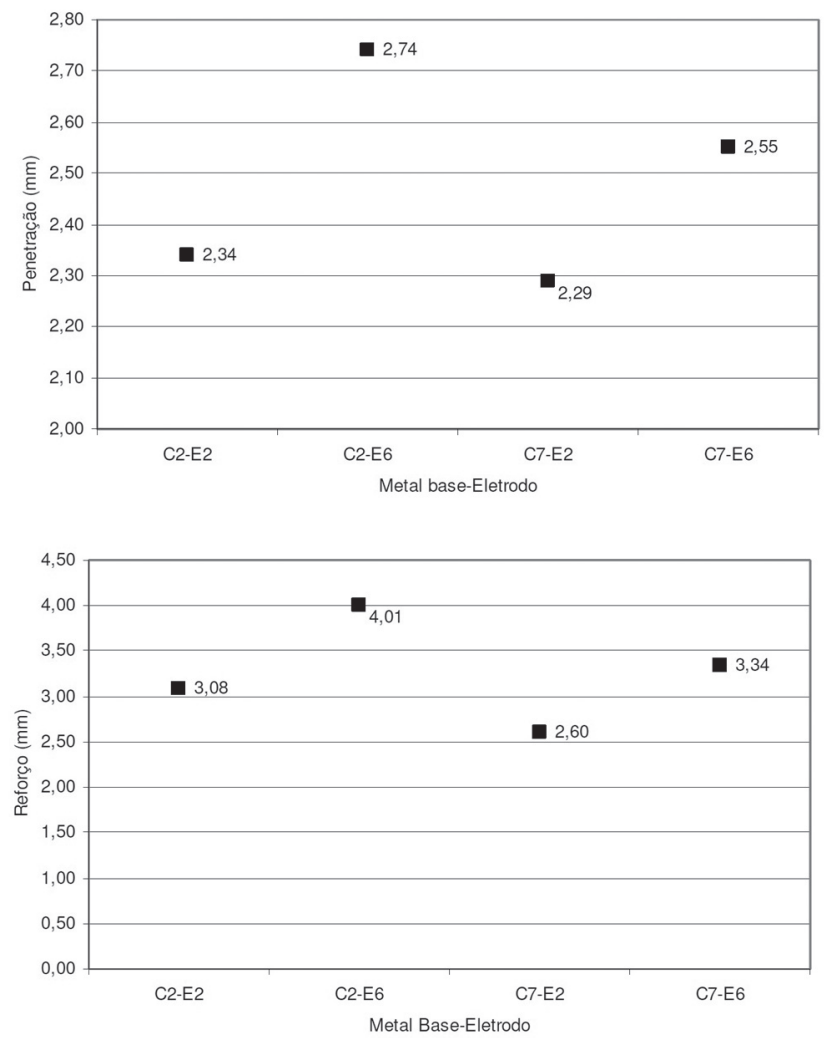

Figura 14: Penetração e reforço médio dos cordões de solda.

Campbell [12] reportou sobre o mecanismo de formação de poros em fundição. Devido à alta pressão parcial das moléculas de CO, elas atuam como sítios para nucleação dos poros. De toda forma, como as moléculas de CO têm baixa mobilidade, elas não contribuem para o crescimento do poro. Por outro lado, o hidrogênio tem alta mobilidade, o que o permite difundir para as bolhas de $\mathrm{CO}$ existentes, acarretando no crescimento do poro.

Assim, parece ser razoável esperar que com o aumento no teor de carbono da alma e metal de base, o número de poros deveria aumentar. Analisando as Figuras 15 e 16, constata-se que o diâmetro dos poros diminui enquanto o número de poros aumenta. A tendência oposta pode ser atribuída a coalescência dos poros, levando a redução do número de poros, mas aumentando a área máxima dos poros (Figura 17) e a área total dos poros (Figura 18).

A redução na área máxima dos poros com o aumento do teor de carbono do metal de base é interessante, pois tem sido reportado na literatura que poros uniformemente distribuídos no metal de solda aumentam a resistência a fadiga do metal de solda devido ao fato destes poros atuarem como pontos de ancoramento de trincas [24].

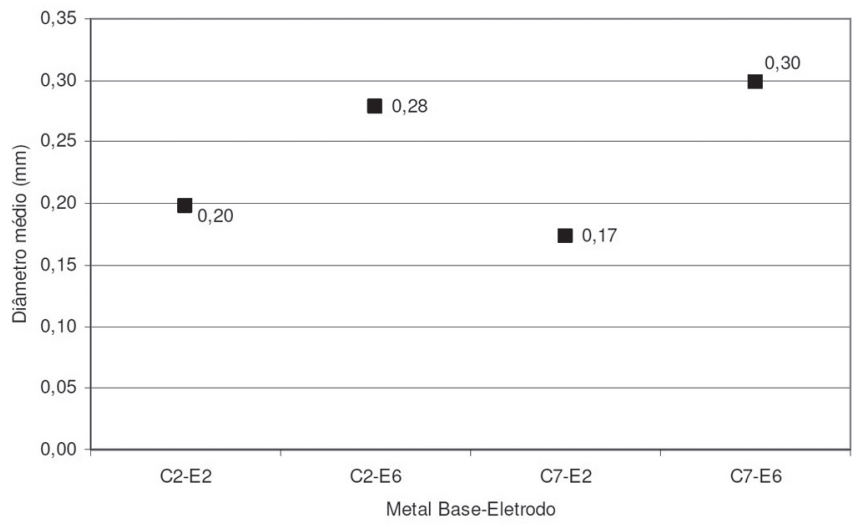

Figura 15: Diâmetro médio dos poros no metal de solda em função do teor de carbono do metal de base e alma do eletrodo.

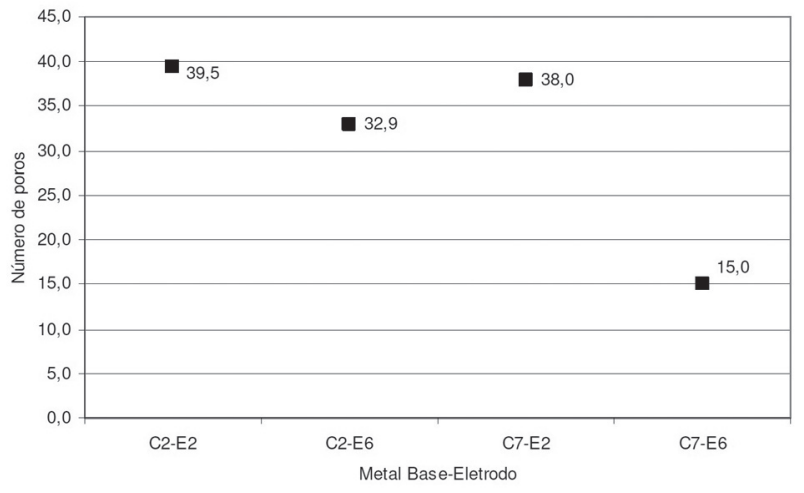

Figura 16: Número de poros em função do teor de carbono da alma do eletrodo e metal de base.

A Figura 17 mostra a área total dos poros no metal de solda. Como pode ser observado, a área total dos poros está de acordo com a porosidade no metal de solda.

A Figura 19 mostra os resultados da composição química do metal de solda. Como pode ser observado, maiores teores de carbono na alma do eletrodo e metal de base resultaram em um maior teor de carbono do metal de solda. O eletrodo com alma de maior teor de carbono produziu um metal de solda com maiores teores de manganês e silício. O metal de base com maior teor de carbono não alterou os teores de manganês e silício no metal de solda.

O metal de base re-solidificado (área do metal de solda localizado abaixo da linha do metal de base) e reforço foram medidos para se calcular a diluição do metal de base no metal de solda para cada combinação eletrodo-metal de base. Usando-se os valores de diluição, o teor de carbono esperado para o metal de solda pode ser estimado, desconsiderando as perdas dos elementos e a presença de poros. As Equações 2 e 3 foram utilizadas e os resultados estão mostrados na Tabela 5 . A diferença entre o teor de carbono estimado e mensurado foi maior para os eletrodos de maior teor de carbono na alma. Esses resultados indicam que o carbono (que se esperava que fosse para o metal de solda) foi perdido através da formação de $\mathrm{CO} /$ $\mathrm{CO}^{2}$. 


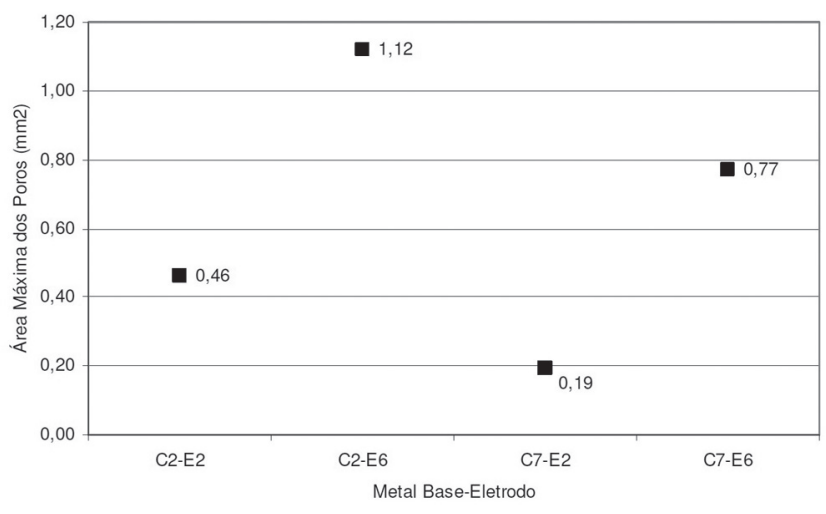

Figura 17: Área máxima dos poros em função do teor de carbono da alma do eletrodo e metal de base.

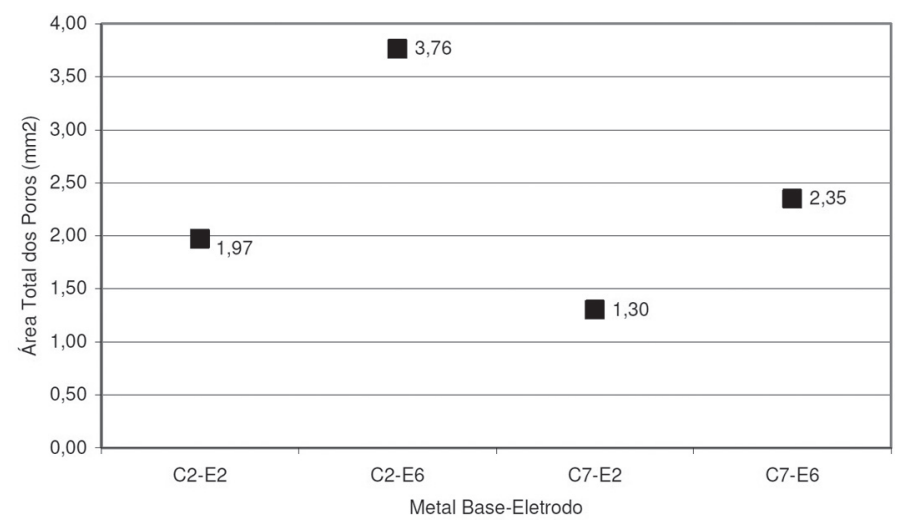

Figura 18: Área total dos poros em função do teor de carbono da alma do eletrodo e metal de base.

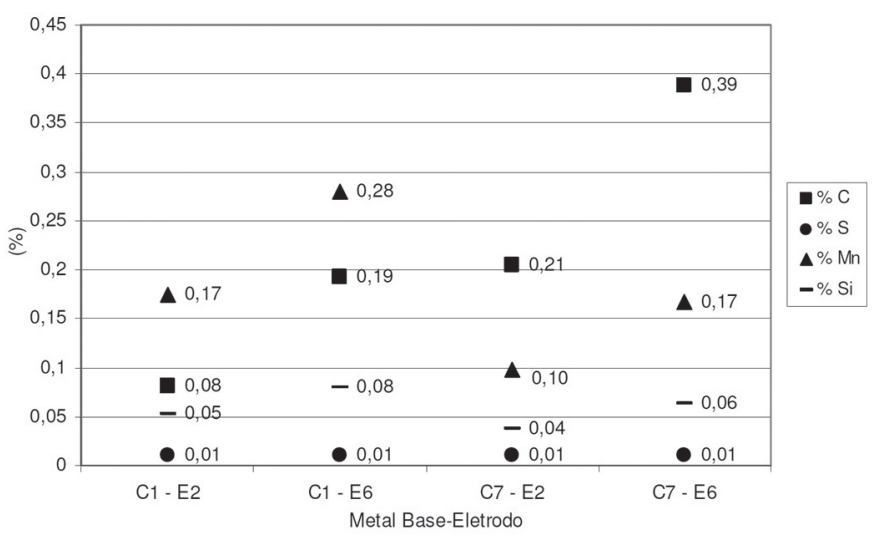

Figura 19: Análise química do metal de solda

A grande diferença entre o carbono estimado e medido para o metal de base pode ser relacionado com a redução da porosidade. Este resultado pode ser explicado pela menor penetração e reforço obtidos usando o metal de base com maior teor de carbono. Menores valores de penetração e reforço permitem que os produtos gasosos escapem mais facilmente, como foi discutido anteriormente.

$C_{M S}=\frac{C_{M A} \cdot(100-D)+C_{M B} \cdot(D)}{100}$
Onde:

$\mathrm{C}_{\mathrm{MS}}=$ Carbono teórico no metal de solda;

$\mathrm{C}_{\mathrm{MA}}=$ Teor de carbono do metal de adição;

$\mathrm{C}_{\mathrm{MB}}=$ Teor de carbono do metal de base;

$\mathrm{D}=$ Diluição;

$D=\frac{A_{M B}}{A_{M B}+A_{M A}}$

$\mathrm{A}_{\mathrm{MB}}=$ Área do cordão de solda abaixo da linha do metal de base.

$\mathrm{A}_{\mathrm{MA}}=$ Área do cordão de solda acima da linha do metal de base.

Tabela 5: Diferença entre o carbono esperado para o metal de solda e o que realmente foi transferido.

\begin{tabular}{|c|c|c|c|}
\hline \multicolumn{4}{|c|}{ Delta (\%) (Carbono teórico - medido) } \\
\hline C2-E2 & C2-E6 & C7-E2 & C7-E6 \\
\hline-0.0036 & -0.2197 & -0.1041 & -0.3510 \\
\hline
\end{tabular}

\section{Conclusões}

Baseado nos resultados deste estudo do efeito do teor de carbono da alma do eletrodo e metal de base sobre a porosidade chegou-se as seguintes conclusões:

1) O eletrodo com maior teor de carbono produziu soldas com maior porosidade. Tal fato foi relacionado com o aumento do número de curtos-circuitos na transferência metálica e oxidação do carbono na gota;

2) O metal de base com maior teor de carbono produziu soldas com menor porosidade. Isto foi relacionado com o menor reforço e penetração apresentado pelos cordões de solda nesta condição;

3) O carbono na alma do eletrodo é efetivo para mitigar a perda de manganês e silício do metal de solda.

\section{Agradecimentos}

Os autores agradecem pelo suporte recebido do Center for Welding, Joining and Coatings Research - Colorado School of Mines-EUA, Conselho de Desenvolvimento Científico e Tecnológico-Brasil e ESAB-Brasil S.A.

\section{Referências Bibliográficas}

[1] PEREZ, F. The Mechanism of Porosity Formation in Underwater Steel Welds using SMAW Process. Golden, Colorado, EUA, Colorado School of Mines, Thesis, 183f, 2007.

[2] PESSOA, E.C.P. Study of Porosity Variation Along Underwater Wet Welds, Belo Horizonte, Minas Gerais - Brazil: Universidade Federal de Minas Gerais, Thesis, 2007 - in Portuguese.

[3] PESSOA, E. C. P., BRACARENSE, A. Q., LIU, S., GUERRERO, F. P., ZICA, E. M. Porosity Variation Along Multipass Underwater Wet Welds and its Influence on Mechanical Properties, Journal of Materials Processing Technology Elsevier - EUA, v. 179, p. 239-243, 2006. 
[4] ROWE M. D., LIU S. e REYNOLDS T. J. The Effect of Ferro-Alloy additions and Depth on the Quality of Underwater Wet Welds. Welding Journal, August 2002, pp. 156-S-166-S, 2002.

[5] OLSON, D.L., LIU S. and IBARRA, S. "Pyrometallurgy and Physical Metallurgy of Underwater Wet Welds", in Conf. Proc. on 'Welding Technology in Action - Vol. 2', Paper 25, Melbourne, Australia, October 1994.

[6] SUGA, Y., HASUI, A. On Formation of Porosity in Underwater Weld Metal, Transactions of the Japan Welding Society, Vol. 17, $\mathrm{N}^{\circ} .1,1986$.

[7] TSAI, C. L. MASUBUCHI, K. Interpretive Report on Underwater Welding, Welding Research Council Bulletin, 224, February, 37pg, 1977.

[8] SANTOS, V. R., POPE, A. M., TEIXEIRA, J. C. G. Evaluation of the Use of Oxidants electrodes in Underwater Wet Welding. Latin American Congresso of Welding. Rio de Janeiro, 1992. - in Portuguese.

[9] WATSON, P.D., TSAI, C.L., WOOD, B. Fitness for service Design Application for Underwater Wet Welds, International Workshop on Underwater Welding of Marine Structures, Lousiana, USA, pp.201-236, 1994.

[10] GRONG, O. Metallurgical Modelling of Welding. (2th Edition), Woodhead Publishing, 1997. Online version available at: http://www.knovel.com/knovel2/Toc. jsp?BookID $=1281 \&$ VerticalID $=0$

[11] BRANDI, S., TANIGUCHI, C. e LIU, S. Analysis of Metal Transfer in Shielded Metal Arc Welding. Welding Journal 70(10): 261s-270s, 1991.

[12] CAMPBELL, J. Castings. Elsevier, 2001. Online version available at:

ht t p://ww w. knove 1. com/knove $12 /$ Toc. jsp? BookID $=711 \&$ VerticalII $=0$

[13] PINTO, L., C. M. Quantikov, Um Analisador Microestrutural Para Ambiente Windows. Thesis. Usp/INPE. Brasil, 1996.

[14] SILVA, W. C. D., ANDRADE, L. G. D. RIBEIRO, L. F., BRACARENSE, A.Q. and PESSOA, E. C. P., Effect of Electrode Core Rod and Base Metal Carbon Content in Underwater Wet Weld Morphology. IX Congresso Nacional de Engenharia Mecânica e Industrial, Brazil, 2009. - in Portuguese. [15] HEIPLE, C. and ROPER., J., 1982, Mechanism For Minor Element Effect On Gta Fusion Zone Geometry, Welding Journal, vol.61, n.4, pp. 97-102.

[16] KEENE, B., 1988, Review Of Data For The Surface Tension Of Iron And Its Binary Alloys, International Material Review, vol.33, n.1, pp. 1-37.

[17] KOU, S., 2003, Welding Metallurgy, Wiley-Interscience.

[18] KOU, S. and LIMMANEEVICHITR, C., 2000, Visualization Of Marangoni Convection In Simulated Weld Pools Containing A Surface-Active Agent, Welding Journal, vol.79, n.11, pp. 324330.

[19] KOU, S. and LIMMANEEVICHITR, C., 2000, Visualization Of Marangoni Convection In Simulated Weld Pools, Welding Journal, vol.79, n.5, pp. 126-135.

[20] LIU, S., POPE, A.M., and DAEMEN, R., 1994, Welding Consumables And Weldability, International Workshop on Underwater Wet Welding of Marine Structures, pp.321-350.
[21] MILLS, K. C. and KEENE, B.J., 1990, Factors Affecting Variable Weld Penetration, International Material Reviews, vol. 35, n.4, pp. 185-216.

[22] GOOCH, T. G. Properties of Underwater Welds. Part 1. Procedures Trials. Metal Construction, pp.164-167, vol.8, March, England, 1983.

[23] SILVA, E. A.; HAZLETT, T. H.; Shielded Metal Arc Welding Underwater With Iron-Powdered Electrodes, Welding Journal, 50 (6), June, 406-415, 1971.

[24] LORENZO, R. F. D., BRACARENSE, A. Q., PESSOA, E. C. P., Discontinuities evaluation on submerged wet welds. 18th International Congress of Mechanical Engineering: 18th International Congress of Mechanical Engineering, Ouro Preto, MG., 2005 - Brazil. 